\title{
Systematic analysis of X-inactivation in 19 XLMR families: extremely skewed profiles in carriers in three families
}

\author{
Martine Raynaud ${ }^{1,2}$, Marie-Pierre Moizard ${ }^{1}$, Benoît Dessay ${ }^{1}$, Sylvain Briault ${ }^{1}$, \\ Annick Toutain ${ }^{1}$, Chantal Gendrot ${ }^{2}$, Nathalie Ronce ${ }^{1}$ and Claude Moraine ${ }^{1}$ \\ ${ }^{1}$ Unité de Génétique et INSERM U316; ${ }^{2}$ Laboratoire de Biochimie et Biologie Moléculaire et IN SERM U316, Hôpital \\ Bretonneau, Tours, France
}

\begin{abstract}
It has been demonstrated in several X-linked disorders, both with and without mental retardation, that the $X$-inactivation process plays a significant role in the expression of $X$-linked diseases in females. Moreover, in some disorders extremely skewed inactivation of the $X$ chromosome is constant in carriers, and this is thought to result from a proliferation or a survival advantage for cells expressing the normal allele at this locus over cells expressing the mutated allele. X-linked mental retardation (XLMR) is heterogeneous, and cloning and characterization of the mutated genes are in progress. XLMR can be expressed in carrier females but often with milder manifestations. We report the systematic study of the X-inactivation profile of obligate carriers and other females in 19 multiplex XLMR pedigrees, using leucocyte-extracted DNA. Extremely skewed profiles were observed in carriers in three of 19 families. European Journal of Human Genetics (2000) 8, 253-258.
\end{abstract}

Keywords: skewed X-inactivation; XLMR carriers; mental retardation

\section{Introduction}

XLMR disorders include specific conditions (MRXS), which are characterised by consistent neuromuscular, metabolic or physical abnormalities, and non-specific conditions (MRX) in which mental retardation (MR) is the only trait. ${ }^{1} X L M R$ accounts for the excess of males in mentally deficient individuals ${ }^{2}$ but some carrier females are also affected in MRX and MRXS families. ${ }^{1,3}$ There is strong evidence that the penetrance of mental retardation in carrier females may be related to the randomness or skewing of $X$-inactivation in critical tissues ${ }^{4}$ but systematic evaluation of $X$-inactivation profiles has not so far been reported in XLMR families.

$X$-inactivation profiles have been evaluated in several $X$-linked disorders with or without mental retardation in order to understand the female phenotypes (reviewed by Belmont ${ }^{5}$ ). We report the systematic study of the $\mathrm{X}$-inactivation profile of obligate carriers and other females

Correspondence: Dr Martine Raynaud, Unité de Génétique et INSERM U316, Hôpital Bretonneau, 2 bd Tonnellé, 37044 Tours, Cedex 1, France. Tel: +33247474799; Fax: +33247618256; E-mail: raynaud@med.univ-tours.fr

Received 11 June 1999; revised 19 November 1999; accepted 23 November 1999 in 19 multiplex XLMR pedigrees. This study could explain the phenotypes in females and provide information about the mutated gene expression and normal gene function compared with other $\mathrm{X}$-linked conditions.

\section{Materials and methods}

Clinical and linkage analysis and $\mathrm{X}$-chromosome inactivation profile study were performed on blood leukocyteextracted DNA in 143 females from 19 large XLMR multiplex families (at least two affected males born of two femalerelated siblings). All females in each family, whether obligate carriers ( 50 females) or of unknown status, were investigated for X-inactivation when DNA was available. Lymphoblastoid cell line-extracted DNA was not used for the $X$-inactivation PCR assays because the cultured cell population may not reflect the in vivo cell population. X-chromosome inactivation analysis was performed using two PCR assays: Hpall digestion and either androgen-receptor (AR) gene polymorphic trinucleotide ${ }^{6}$ of FMR 1 variable CGG repeat. ${ }^{7}$ The density of the bands was quantitated visually and by image analysis (software package Bioprofil, Vilber Lourmat system: Vilber Lourmat, Marne-La-Vallée, France). In some cases, 


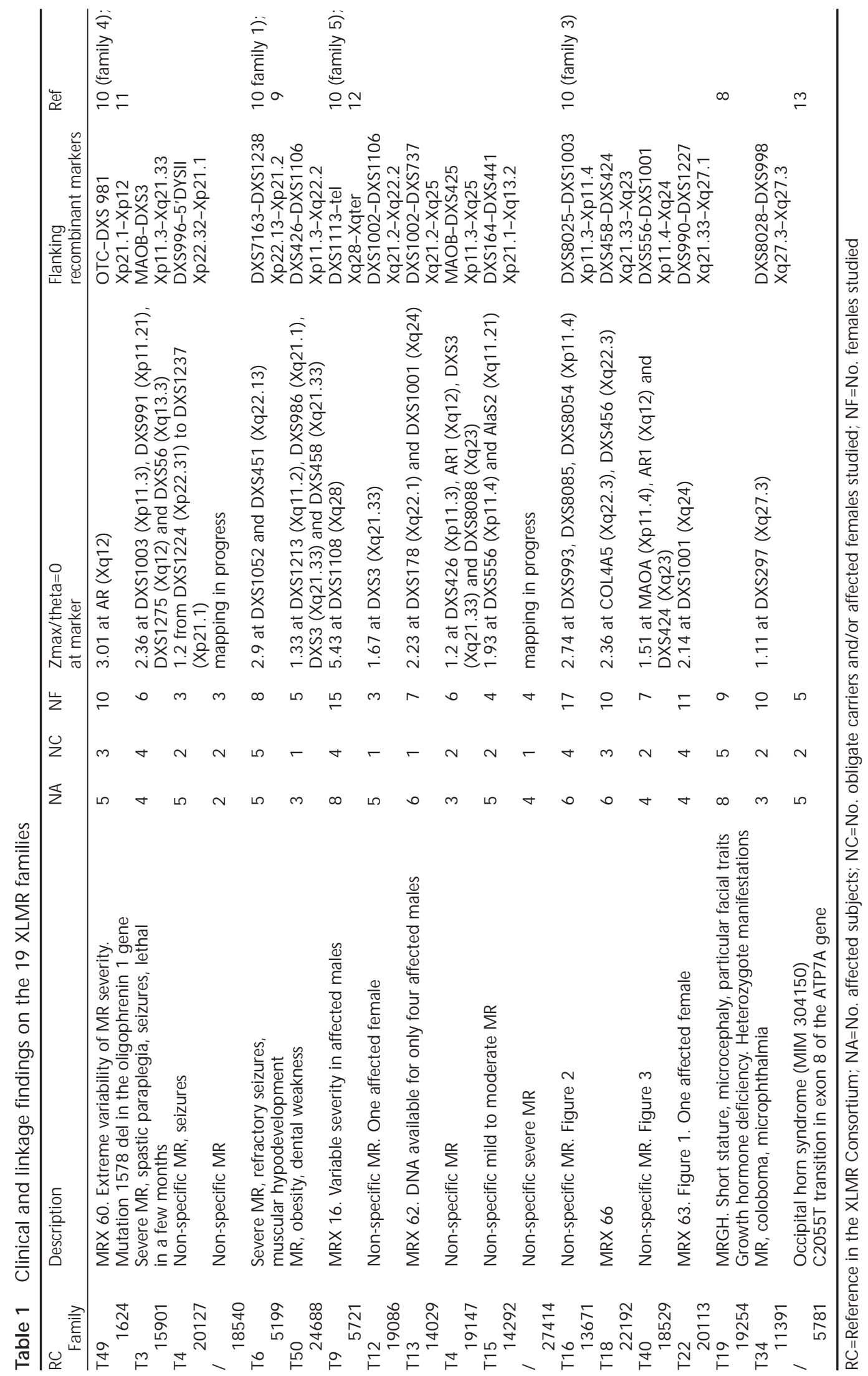


allelic fragments differed by one repeat and the additional bands that resulted from DNA strand slippage during amplification made it impossible to analyse the relative intensity (NA) of each fragment. In others the microsatellite was not informative (NI). After systematic exclusion of FRAXA, FRAXE and ATRX syndromes linkage analysis was performed as previously reported. .,9 $^{8}$

\section{Results}

Clinical and linkage information on each of the 19 families is schematically set out in Table1. Linkage to the other $X$ chromosome regions was excluded. Three MRX families of the 19XLMR families showed extremely skewed inactivation profiles ( $85 \%$ : $15 \%-100 \%$ : $0 \%$ ) in obligate carriers, a pattern that was found only in three of 32 female controls analysable for the AR assay, and the maternally-inherited X chromosome was always the inactive one. The three pedigrees are shown in Figures 1, 2 and 3. Clinical and neuropsychological data will be reported elsewhere. Mild to moderate mental retardation was not associated with any biochemical, morphological or neurological abnormalities. A singlefemale was retarded in one family (III2 in Figure1). Clinical and linkage data are summarized in Table 1 and comparison with haplotypes in the localisation area can be seen with pedigrees in Figures 1,2 and 3.

The X-inactivation profiles in the remaining 16/19XLMR families were random or moderately skewed. Inactivation studies of two of the 16 families have previously been reported, along with the clinical and linkage findings. ${ }^{8,9}$

\section{Discussion}

As explained by Martinez et al, ${ }^{14}$ the probability of extremely skewed X-inactivation occurring by chance in four, five or six females in the same family for the chromosome associated with the disease is very weak. $\mathrm{X}$-autosome translocation and large deletions were excluded by karyotype for the three families. Two main explanations for extremely skewed $X$-inactivation therefore remain to be discussed. First, skewed

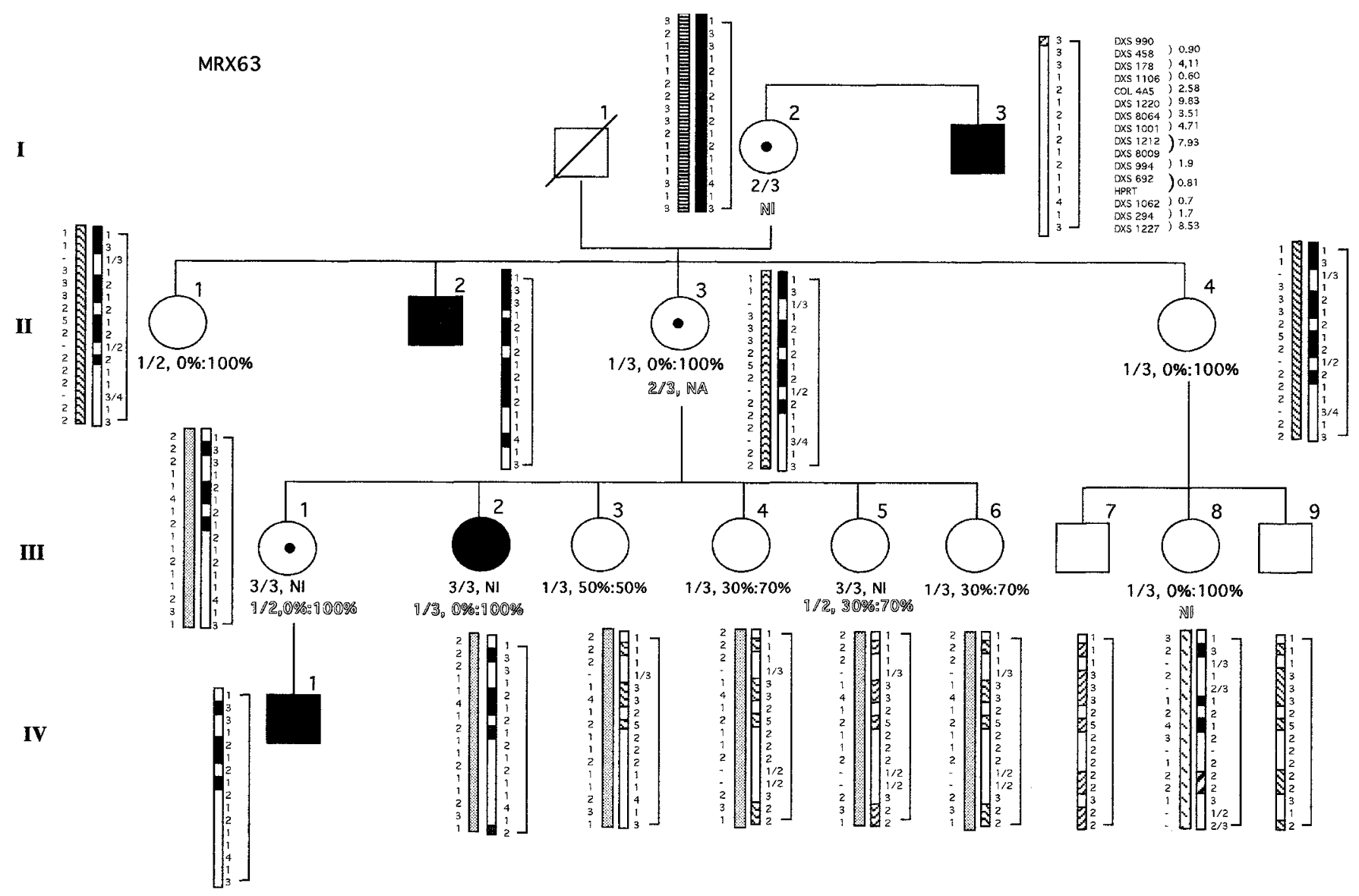

Figure 1 Family pedigree and haplotypes for the polymorphic markers corresponding to the linkage region. Black symbols denote affected subjects. Standard nomenclature is used for all symbols. Bold type: AR/Hpall analysis; outline type: FMR/Hpall analysis; NI: not informative; NA: not analysable (allelic fragments differing by only one repeat). Alleles are numbered arbitrarily in each family. Numbers are followed by the proportions of density in each allele. The localisation area between the flanking recombinant markers is showed by a line. Genetic distances (GDB 1998) are behind the markers. 


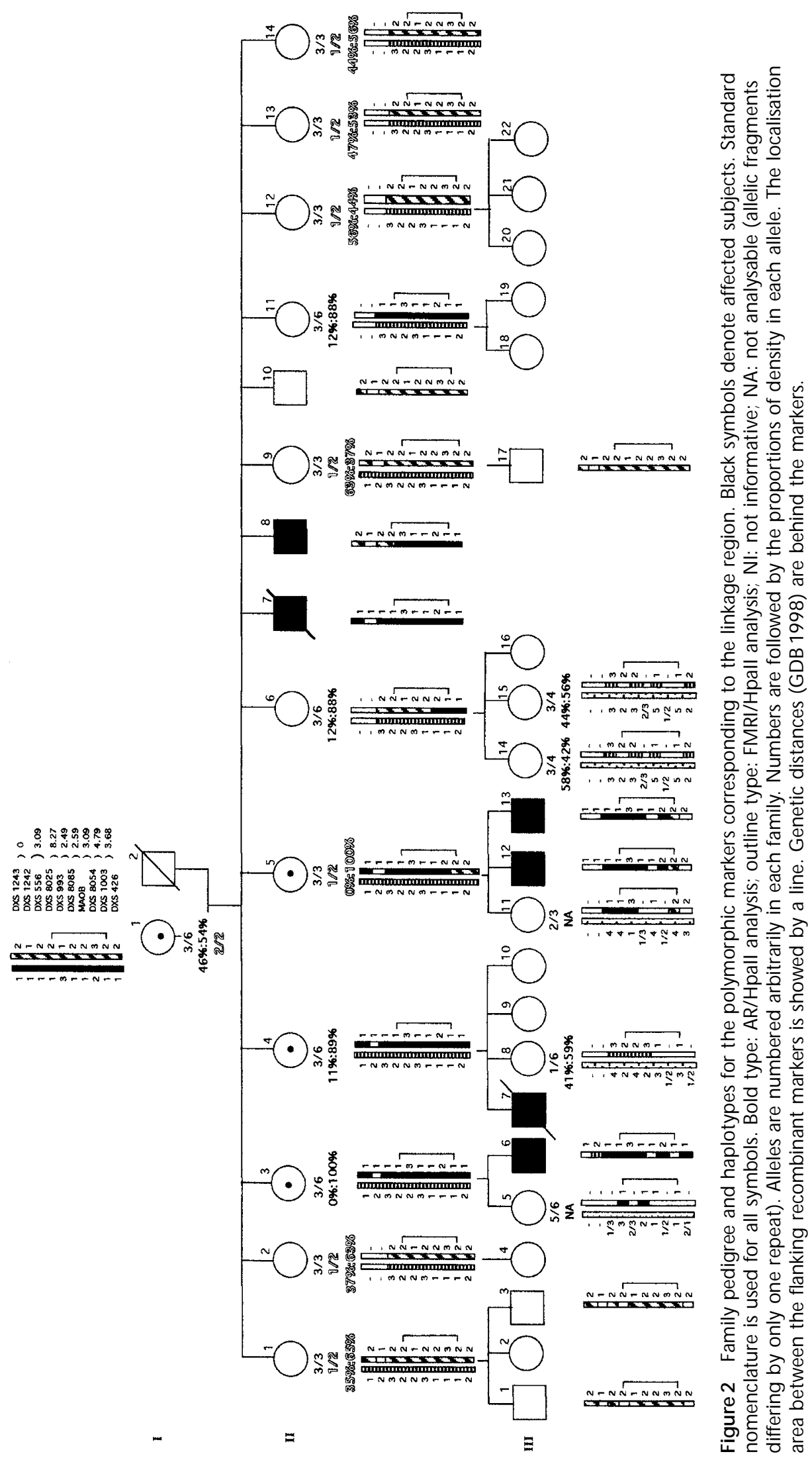




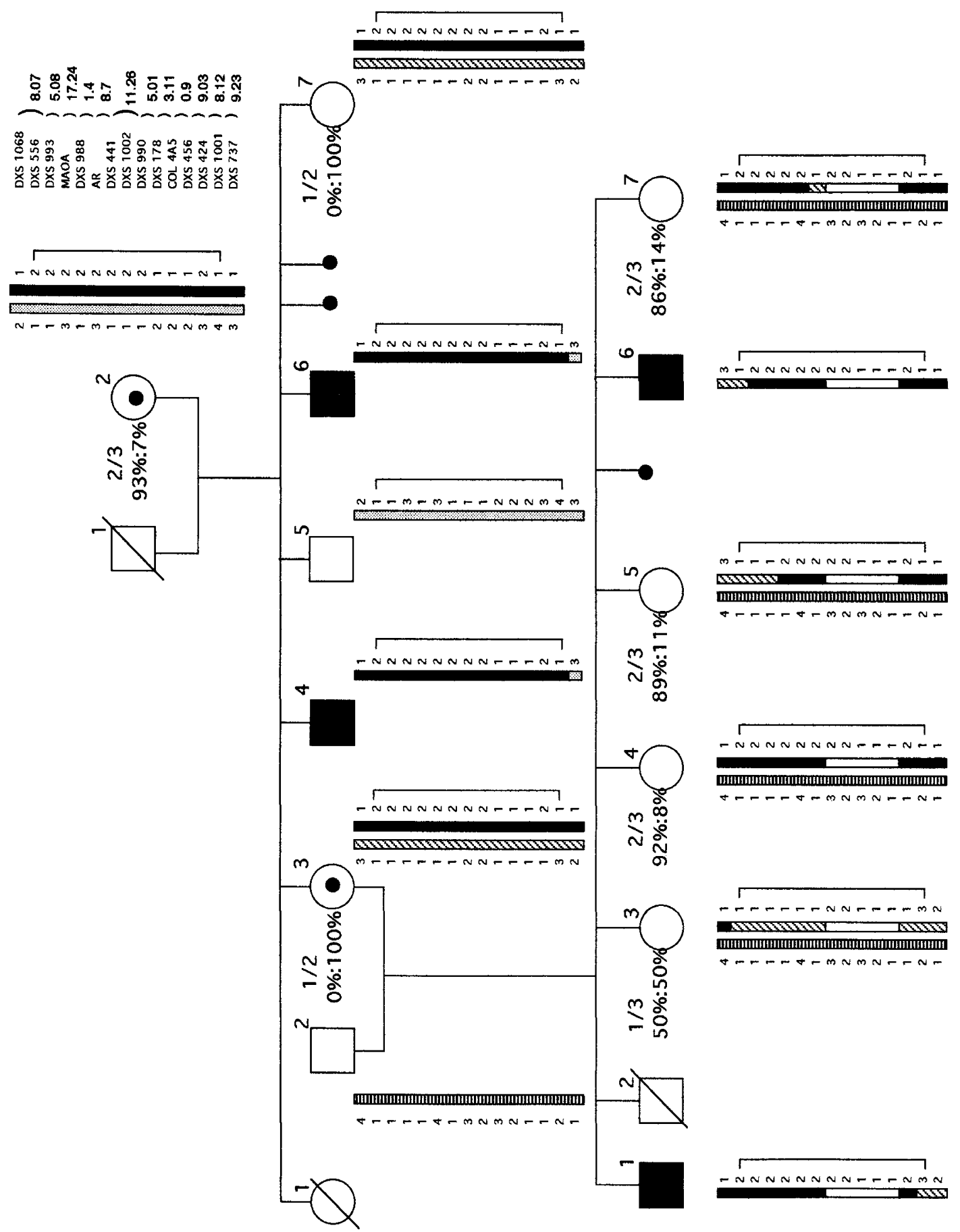

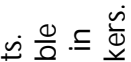

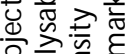

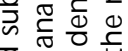

원둥무

过菦

눈은

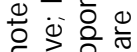

过 흥

늘 छ

을 $\stackrel{\circ}{=}$

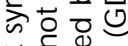

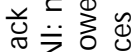

$\bar{n} \overline{\overline{0}}$

둔

递宁

ธे एँ

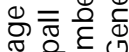

동

Q

$\mp \sum_{i} \overline{\bar{\varepsilon}} \bar{\sigma}$

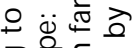

인등 웅

흥 \&

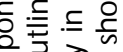

कृ 0 츠는

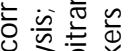

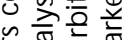

जू워

흠ำ

ह $\overline{\bar{\sigma}} \frac{1}{\overline{0}}$

늘 들을

잉 ฮ

हญ ญ ฮ

흥히잉

으믐 $\frac{\bar{v}}{\bar{y}}$

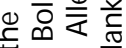

는 능 뭠

पै है

हो

음 $\overline{0}$ 둥

흔 흐

든 중

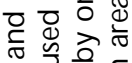

\& 느 응흐

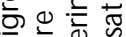

过豆出

츨ㄴㄷㄴ든

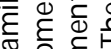

듣 हैㅇํㅇ

$m$ 递选

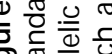

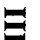

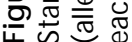


$X$-inactivation may be a familial trait reflecting inheritance of a genetic factor that controls the randomness or nonrandomness of $X$-inactivation. Alternatively, skewed inactivation may reflect the segregation of a defect influencing cell survival or proliferation (the effect may be limited to leucocyte cells). The precise cosegregation of the skewed $\mathrm{X}$-inactivation profile in leukocytes and the M RX carrier trait in the three families reported here makes the second explanation more likely. The suspected defect that gives a proliferative or survival advantage to cells might be the disease gene itself or, less likely, a contiguous gene that might have been removed by a submicroscopic deletion.

A random pattern of $\mathrm{X}$-chromosome inactivation was observed for the oldest carrier female in one of our three families reported above (I 1 in Figure2, 66 years old). Conflicting results have been reported about the stability of $X$-inactivation in females $>60$ years old. Further studies should clarify this. Identification of carriers among potential female carriers in X-linked disorders is not always possible, even when the mutated gene has been mapped by linkage analysis, because of the possible occurrence of recombinations in the localisation area itself (eg recombination in DXS692 for female III8 in Figure1 and recombination in MAOB for 116 in Figure2). The X-inactivation profile can be taken into account in evaluating the carrier risk for these females, as in ATRX syndrome. ${ }^{15}$ Moreover, taking into account the linkage data from females with known status, with a calculated probability from their $X$-inactivation profile, may reduce the localisation area to the region that they share with affected males and carrier females in the family. For the family in Figure1, the localisation area would be DXS990-DXS692 (Xq21.33-Xq26.1) instead of DXS990DXS1227 (Xq21.33-Xq27.1). For the family in Figure2 it would be MAOB-DXS1003 (Xp11.3-Xp11.4) instead of DXS8025-DXS1003 (Xp11.3-Xp11.4).

The skewed $X$-inactivation in leucocyte DNA provided evidence that the gene co-segregating with mental retardation in these three families (the MR gene itself or the contiguous gene) is expressed in leukocytes as a cell population.

In the 16/19XMLR families with random or moderately skewed profiles, with possible or constant expressing carriers, the X-inactivation profiles in leukocytes were not correlated with phenotypes, as observed by Des Portes et $\mathrm{al}^{3}$ in M RX 48. Moreover, despite extremely skewed inactivation in leukocyte cells, like the other obligate carriers from family M RX63, III 2 was affected. The $X$-inactivation profile may be different in some critical tissue and this may explain the unexpected phenotypes. Another explanation for the phenotype differences in females that are not correlated with the $X$-inactivation profile is the genetic background and the influence of the other genes in each individual. Variable severity is often observed in males in XLMR families.

Lastly, why a disorder that is not very severe in males and limited to mental retardation, as observed in our three families with extremely skewed X-inactivation in females, is responsible for a selection mechanism in femal ecells remains to be understood.

\section{Acknowledgements}

We wish to thank the families for their cooperation, Sophie Mauve for coordination of family studies, and Marie-N oëlle Marson for technical assistance. We also thank Doreen Raine for editing the English language, Brigitte Jauffrion for lymphoblastoid cell lines, and Professor Alain Goudeau for allowing the use of his densitometer. This work was partly supported by AFM (Association Française contre les Myopathies) and GREG (Groupement de Recherches et d'Etudes sur les Génomes). Our group is a member of the European XLMR Consortium.

\section{References}

1 Lubs HA, Chiurazzi P, Arena JF, Schwartz C, Tranebjaerg L, Neri G: XLMR genes: update 1998. Am J Med Genet 1999; 83: 237-247.

2 Stevenson RE, Schwartz CE, Arena JF, Lubs HA: X-linked mental retardation: the early era from 1943 to 1969. Am J M ed Genet 1994; 51: 538-541.

3 Des Portes V, Billuart P, Carrier A et al: A gene for dominant nonspecific X-linked mental retardation located in Xq28. Am J Hum Genet 1997; 60: 903-909.

4 Willard HF: X chromosome inactivation and X-linked mental retardation. Am J Med Genet 1996; 64: 21-26.

5 Belmont JW: Genetic control of $X$ inactivation and processes leading to X-inactivation skewing. Am J Hum Genet 1996; 58: 1101-1108.

6 Allen RC, Zoghbi HY, Moseley AB, Rosenblatt HM, Belmont JW: Methylation of Hpall and Hhal sites near the polymorphic CAG repeat in the human androgen-receptor gene correlates with $X$ chromosome inactivation. Am J Hum Genet 1992; 51: 1229-1239.

7 Carrel L, Willard HF: An assay for $X$ inactivation based on differential methylation at the fragile X locus, FMRI. Am J Med Genet 1996; 64: 27-30.

8 Raynaud M, Ronce M, Ayrault A-D, Francannet C, Malpuech G, Moraine $\mathrm{Cl}$ : X-linked mental retardation with isolated growth hormone deficiency is mapped to Xq22-Xq27.2 in onefamily. Am J Med Genet 1997; 76: 255-261.

9 Ronce N, Raynaud M, Toutain A et al: Evidence for a new X-linked mental retardation gene in Xp21-Xp22. Clinical and molecular data in one family. Am J Med Genet 1999; 83: 132-137.

10 Moraine C, Dessay B, Toutain A, Briault S, Gendrot C, Ronce N: $X$-linked mental retardation: linkage results in five unrelated families. Am J Hum Genet 1994; 55: A196, 1141.

11 Billuart $\mathrm{P}$, Bienvenu $\mathrm{T}$, Ronce $\mathrm{N}$ et al: Oligophrenin-1 encodes a rhoGAP protein involved in $\mathrm{X}$-linked mental retardation. Nature 1998; 392: 923-926.

12 Gendrot C, Ronce N, Raynaud M et al: X-linked non-specific mental retardation (MRX16) mapping to distal Xq28: linkage study and neuropsychological data in a large family. Am J Med Genet 1999; 83: 411-418.

13 Ronce N, Moizard MP, Robb L, Toutain A, Villard L, Moraine C: A C2055T transition in exon 8 of the ATP7A gene is associated with exon skipping in an occipital horn syndrome family. Am J Hum Genet 1997; 61: 233-238.

14 Martinez F, Tomas M, Millan JM, Fernandez A, Palau F, Prieto F: Genetic localisation of mental retardation with spastic diplegia to the pericentromeric region of the $\mathrm{X}$ chromosome: $\mathrm{X}$ inactivation in female carriers. J Med Genet 1998; 35: 284-287.

15 Gibbons RL, Suthers GK, Wilkie AOM, Buckle VJ, Higgs DR: X linked al pha-thalassaemia/mental retardation (ATRX) syndrome: localization to $X q 12-q 21.31$ by $X$ inactivation and linkage analysis. Am J Hum Genet 1992; 51: 1136-1149. 